\title{
Transcriptional response of pancreatic beta cells to metabolic stimulation: large scale identification of immediate-early and secondary response genes
}

\author{
Dominique A Glauser ${ }^{1}$, Thierry Brun ${ }^{2}$, Benoit R Gauthier ${ }^{2}$ and \\ Werner Schlegel*1
}

Address: ${ }^{1}$ Fondation pour Recherches Médicales, University of Geneva, Av. de la Roseraie 64, 1211 Geneva, Switzerland and ${ }^{2}$ Department of Cell Physiology and Metabolism, University Medical Center, Rue Michel-Servet 1, 1211 Geneva, Switzerland

Email: Dominique A Glauser - dominique.glauser@medecine.unige.ch; Thierry Brun - thierry.brun@medecine.unige.ch; Benoit R Gauthier - benoit.gauthier@medecine.unige.ch; Werner Schlegel* - werner.schlegel@medecine.unige.ch

* Corresponding author

Published: 22 June 2007

BMC Molecular Biology 2007, 8:54 doi:10.1186/1471-2199-8-54

This article is available from: http://www.biomedcentral.com/I47|-2/99/8/54

(C) 2007 Glauser et al; licensee BioMed Central Ltd.

This is an Open Access article distributed under the terms of the Creative Commons Attribution License (http://creativecommons.org/licenses/by/2.0), which permits unrestricted use, distribution, and reproduction in any medium, provided the original work is properly cited.

\begin{abstract}
Background: Physiological long term adaptation of pancreatic beta cells is driven by stimuli such as glucose and incretin hormones acting via CAMP (e.g. GLP-I) and involves regulated gene expression. Several rapidly inducible immediate-early genes (IEGs) have been identified in beta cells. Many of these IEGs code for transcription factors and have the potential to control the transcription of downstream target genes likely involved in long term cellular adaptation. The identity of these target genes has not been determined, and the sequence of events occurring during beta cell adaptation is still unclear.
\end{abstract}

Results: We have developed a microarray-based strategy for the systematic search of targets. In Min6 insulin-secreting cells, we identified 592 targets and I 278 IEGs responding to a co-stimulation with glucose and cAMP. Both IEGs and targets were involved in a large panel of functions, including those important to beta cell physiology (metabolism, secretion). Nearly 200 IEGs were involved in signaling and transcriptional regulation. To find specific examples of the regulatory link between IEGs and targets, target promoter sequences were analyzed in silico. Statistically significant overrepresentation of AP-I response elements notably suggested an important role for this transcription factor, which was experimentally verified. Indeed, cell stimulation altered expression of IEG-encoded components of the AP-I complex, activating AP-I-dependent transcription. Loss and gain-of-function experiments furthermore allowed to validate a new AP-I regulated gene (sulfiredoxin) among the targets. AP-I and sulfiredoxin are sequentially induced also in primary cells from rat islets of Langerhans.

Conclusion: By identifying IEGs and their downstream targets, this study brings a comprehensive description of the transcriptional response occurring after beta cell stimulation, as well as new mechanistic insights concerning the AP-I transcription factor. 


\section{Background}

In mammals, blood glucose homeostasis is subjected to a tight endocrine control relying notably on insulin-producing beta cells from the pancreas. Beta cells secrete insulin in response to increased glucose concentrations and to hormones released from gut cells, like glucagon-like peptide-1 (GLP-1). In longer term, these physiological signals also control insulin production, stimuli-responsiveness and beta cell mass [1-4]. Over the years, this regulation helps the organism maintaining glucose homeostasis, accommodating changes in diet and insulin demand. Deficient adaptation may lead to diabetes $[5,6]$.

Long term adaptation of beta cell is associated with changes in gene transcription. Several glucose-regulated genes have been identified which are likely involved in the chronic effects of glucose on beta cell mass and function $[3,7,8]$. Some of these genes are immediate-early response genes (IEGs) rapidly induced upon acute beta cell stimulation with glucose and other stimuli $[7,9,10]$.

IEGs are defined as genes which transcription is regulated without the need for protein de novo synthesis. Induction of IEG transcription is triggered by intracellular signals which activate constitutively expressed transcription factors acting on IEG promoters $[11,12]$. In beta cells, the mechanisms leading to the induction of IEGs by glucose and GLP-1 were shown to involve generation of CAMP, as well as cell depolarization and subsequent $\mathrm{Ca}^{2+}$ signaling, resulting in activation of calmodulin-dependent kinase IV, protein kinase A and extracellular signal-regulated kinase $1 / 2$. These kinases lead to phosphorylation and activation of several transcription factors, like cAMPresponsive element binding protein, serum response factor, and Elk-1 [13-16]. These mechanisms occur rapidly and result, within minutes, in transcriptional regulation of IEGs. Such direct and rapid mechanisms do not however permit to understand regulation of genes for which expression levels change later and over much longer time frames (hours, days), and which are likely relevant for the long term adaptation of beta cell. Other types of mechanisms must be taken into account.

The best studied IEGs in beta cells (e.g. c-fos, egr-1, nur77, c-myc) code for transcription factors $[7,9,10,17]$. It has been proposed that these transcription factors will in turn regulate the transcription of downstream target genes (which will be referred as targets throughout this manuscript). The distinction can thus be made between two modes of transcriptional regulation: (i) direct regulation, which is independent of protein synthesis (and concerns IEG induction), and (ii) indirect regulation, which requires preliminary IEG induction (and concerns target gene control). A cascade of gene induction, involving upstream IEGs and downstream targets, represents an attractive model to explain how beta cell can bridge the time gap between relatively short-lived stimuli and long term cellular adaptation of gene expression. [18]

The aims of the study were, first, to identify targets at a large scale in order to evaluate the importance of indirect regulation of gene transcription, second, to define the cellular functions concerned, and third, to verify the regulatory link between specific IEG transcription factors and targets.

We have designed a genome-scaled approach to identify glucose and CAMP-induced IEGs and their targets. Database annotation searches were applied to infer cellular functions of these genes. In silico analysis of target gene promoters as well as gain and loss of function experiments were performed to establish the link between specific IEGs and target gene induction.

The data reported here suggest that a large part of gene expression induced upon beta cell stimulation is regulated by indirect mechanisms requiring preliminary IEG induction. Functions attributed to gene products cover a large spectrum of cellular processes for both IEG and targets, including metabolism, secretion, control of cell growth, signal transduction and regulation of transcription.

\section{Results \\ Identification and validation of glucose- and CAMP- regulated IEGs and targets}

To identify genes regulated by metabolic signals in beta cells, we stimulated Min6 insulin-secreting cells with a combination of elevated glucose $(10 \mathrm{mM})$ and chlorophenylthio-cAMP (cpt-cAMP, $0.2 \mathrm{mM}$ ), a membrane-permeant cAMP analogue. Indeed, glucose induction of gene expression is potentiated by gut hormones (such as glucagon-like peptide-1, GLP-1) which raise cAMP [9]. Our initial transcript profile comparison using high density oligonucleotide microarrays identified genes regulated by a 4 hour treatment with glucose and cpt-cAMP (666 upregulated, 1204 down-regulated; fold change threshold of 1.5). Comparison with profiles obtained in presence of the protein synthesis inhibitor cycloheximide (CHX) allowed classifying each stimuli-responsive gene either as IEG or as target. Indeed, by blocking protein neosynthesis, CHX blocks synthesis of IEG products and their downstream regulatory action on target transcription. Thus, among the stimuli-responsive genes, those still regulated in presence of CHX were defined as IEGs, while those no longer regulated were defined as targets (Figure 1, and Additional file 1).

Among the 1870 regulated genes, 592 target genes were identified (Table 1). Thus, a substantial part of the impact 
A

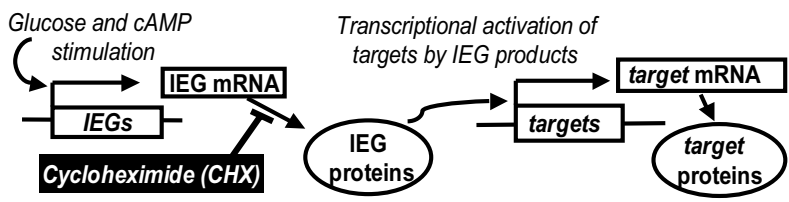

B

\begin{tabular}{lll}
$\begin{array}{l}\text { Experimental } \\
\text { condition comparison: }\end{array}$ & $\begin{array}{l}\text { Differentially } \\
\text { expressed genes: }\end{array}$ & $\begin{array}{l}\text { Deduced gene } \\
\text { list: }\end{array}$ \\
\hline Control vs stimulated & $\begin{array}{l}\text { All responsive genes } \\
\text { (IEGs + targets) }\end{array}$ & Only IEGs \\
\hline $\begin{array}{l}\text { Control vs stimulated } \\
\text { (in presence of CHX) }\end{array}$ & target genes \\
\hline
\end{tabular}

Figure I

Strategy to identify glucose and cAMP responsive IEGs and their downstream targets. A) IEGs (immediateearly genes) are genes which are transcriptionaly inducible in a protein synthesis independent manner. IEG products regulate in turn the transcription of downstream targets.

Cycloheximide (CHX), a protein synthesis inhibitor, blocks IEG product synthesis and subsequent activation of target transcription. B) Genes induced by glucose and cAMP comprise both IEGs and targets. Genes induced by glucose and cAMP in presence of CHX represent only IEGs. Note that $\mathrm{CHX}$ is also present in the control condition for this comparison. Target genes were deduced by subtraction between the gene lists.

produced by metabolic signals on beta cell transcriptional program rely on the indirect action of IEG products.

To validate microarray data, we performed quantitative RT-PCR analysis for a selected set of IEGs and target genes. Comparison between fold-change values obtained from microarray or RT-PCR experiments revealed that the microarray data were of excellent quality (mean difference between microarray and RT-PCR lower than 20\%; see Additional file 2). Furthermore, the CHX effect was confirmed by RT-PCR. Indeed, target regulation by glucose and cAMP was abrogated in presence of CHX (Figure 2). Furthermore, despite a small effect of CHX by itself on all glucose-inducible IEGs examined, these were as strongly stimulated by glucose and cAMP in the presence of CHX

Table I: Number of IEGs and target genes responding to glucose and cAMP identified in the transcript profiling experiment

\begin{tabular}{lccc}
\hline & IEGs & targets & total \\
\hline Up-regulated & 465 & 201 & 666 \\
down-regulated & 813 & 391 & 1204 \\
\hline
\end{tabular}

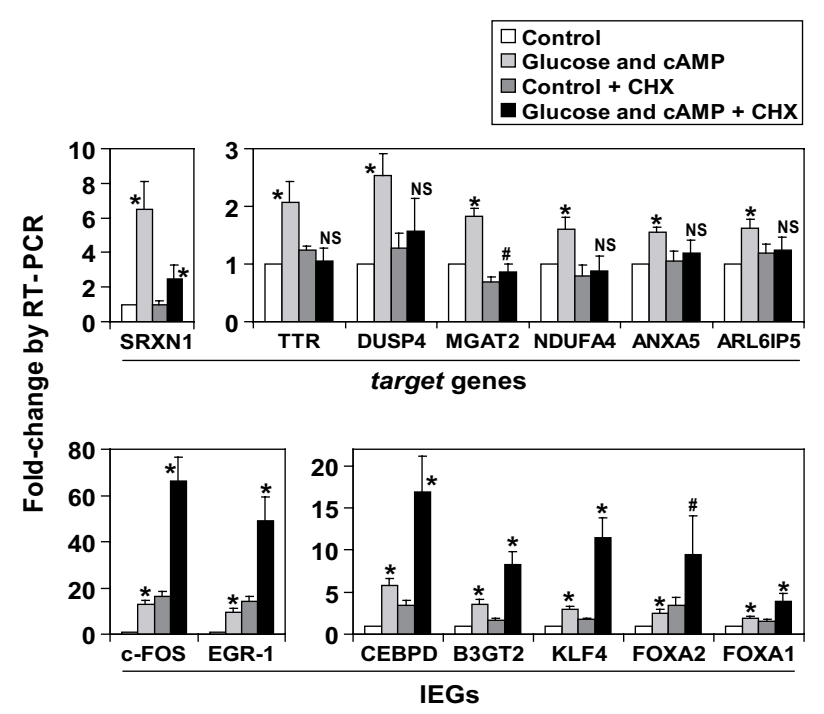

Figure 2

Validation of IEGs and targets by quantitative RT-

PCR. Induction of targets is inhibited in presence of CHX, while induction of IEGs is not. Min6 cells cultured at low glucose for 20 hours were stimulated for 4 hours with $10 \mathrm{mM}$ glucose and $0.2 \mathrm{mM}$ cpt-cAMP, in presence or absence of CHX ( $5 \mu \mathrm{g} / \mathrm{ml}$, added 45 ' prior to stimulation). mRNA levels for indicated genes were assessed by quantitative real-time RT-PCR and normalized with I8S rRNA. Results are expressed as mean of fold change compared to control condition (s.d. as error bars, $\mathrm{n}=5$ ). *, $\mathrm{p}<0.0 \mathrm{I}$; \#, $\mathrm{p}<0.05$; NS: non significant vs respective control condition (i.e with or

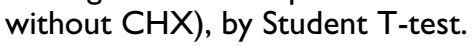

as in its absence (Figure 2). Thus RT-PCR data validate the selection of targets and IEGs based on the microarray data.

\section{Functional classification of IEGs and targets}

To address the functional role of IEGs and targets regulated by glucose and CAMP in beta cells, we classified them into functional categories based on the annotations in the Swiss-Prot database (Figure 3) [19]. Of 755 glucose regulated genes with annotations, more than 200 are involved in signaling and transcription regulation. The large number of IEGs involved in these two processes suggests the importance of indirect mechanisms in gene regulation. Moreover, an important fraction of target genes are themselves involved in signal transduction and transcriptional regulation.

Other important functional clusters include genes involved in the secretory pathway, the metabolism or the control of cell mass; processes that are known to be regulated by glucose in beta cells [8]. Thus, the response of our Min6 model is in agreement with previous knowledge on the effect of metabolic stimuli on gene expression in beta 


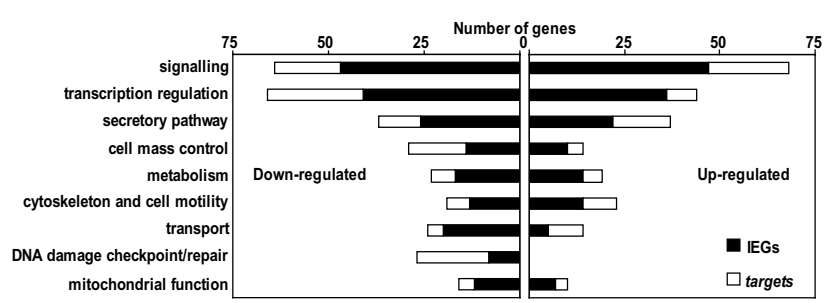

Figure 3

Functional clustering of glucose and CAMP responsive IEGs and targets. From the list of glucose and CAMP regulated transcripts, we retrieved 755 genes with annotations in Swiss-Prot database and clustered them according to functional categories. The diagram depicts the predominant clusters (gathering 534 genes); the 221 remaining genes were found in smaller clusters and are not represented.

cells. The genes involved in the secretory pathway concerned with protein synthesis, translocation and folding in the ER, glycosylation, vesicule transport, and exocytosis, are detailed in the Additional file 3. Interestingly, an important cluster of down-regulated genes is involved in DNA damage checkpoint/repair pathways.

Noteworthy, the roles of IEG products are not restricted to transcriptional regulation and cover a large panel of functions (Figure 3 and Additional file 3). Thus, while on the one hand, some IEGs can act indirectly by regulating expression of target genes, on the other hand, different IEGs can contribute directly to the functional adaptation of beta cell to metabolic stimulation.

Target promoter analysis reveals the importance of AP-I transcription factor

To establish the link between IEGs that encode transcription factors and their targets, we analyzed the promoters of target genes. Predicted regulatory elements in target gene promoters as well as in control sets of promoter (random sets of promoters from genes expressed or not expressed in Min6 cells) were gathered using the TFExplorer database [20]. We then evaluated over- and under-represented regulatory elements in targets promoters compared to control sets. 32 regulatory elements binding specific transcription factors were significantly over-represented in glucoseresponsive target gene promoters $(\mathrm{p}<0.05$; Additional file 4 ). These include notably binding sites for E2F and DP-1 transcription factors found both in up-regulated and down-regulated targets. But the most markedly over-represented regulatory element was an AP-1 binding site which was present in $14 \%$ of the up-regulated targets (Figure 4 ). Interestingly, this binding sequence was not enriched in down-regulated targets. This suggests an important role for AP-1 in transcriptional activation of target, and prompted us to investigate its regulation in more details. $\square$ absent genes

present genes

up-regulated targets

down-regulated targets

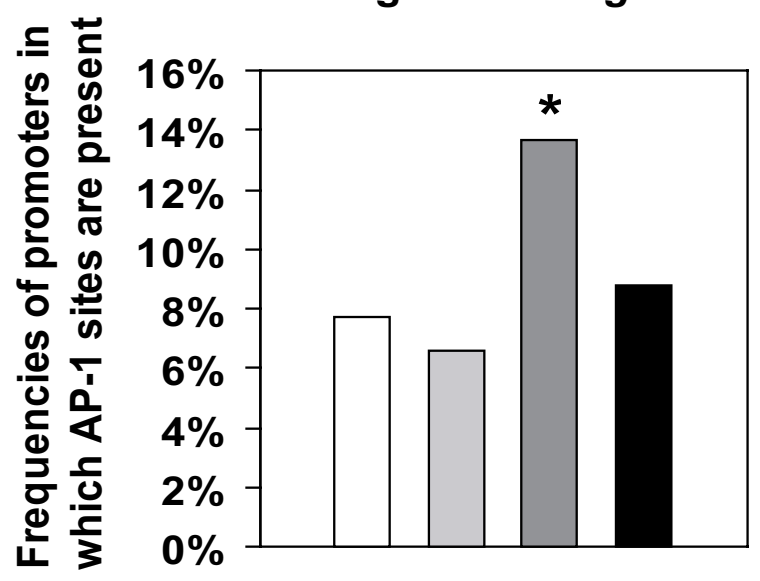

Figure 4

AP-I binding sites are over-represented in promoters of up-regulated targets. Frequencies of promoters containing at least one AP-I binding site were determined using TFExplorer predicted regulatory element database. Among the genes displayed on the microarray, absent genes were those with undetectable expression in Min6 and present genes were those with detectable expression in Min6. *, $\mathrm{p}<$ 0.0 I by Fisher exact test vs present genes.

\section{Glucose and cAMP regulate AP-I complex composition and function}

AP-1 binds DNA as a dimer composed of proteins of the Fos and Jun families; forming either a Jun/Jun homodimer or a Fos/Jun hetero-dimer [21]. Min6 cells maintained at low glucose predominantly expressed c-jun and junD, indicating that the AP-1 complex is likely composed of Jun/Jun homo-dimer (Table 2). Elevated glucose and cAMP produced a robust 10 fold increase in c-fos and fos $B$ (IEGs), while c-jun and junD expression was slightly inhibited (Table 2 and data not shown). These results suggest a potential shift in the composition of the AP-1 complex toward Fos/Jun hetero-dimer and consequently a possible alteration of AP-1 transactivating activity. To test this possibility, we transfected cells with a luciferase reporter gene under the control of an artificial promoter harboring solely AP-1 sites as enhancers (pAP-1-luc; Figure 5A). Cells maintained at low glucose expressed the reporter constitutively, likely reflecting the transcriptional activation by the constitutive (Jun/Jun) AP-1 factors. Despite this relatively high basal level of expression, glu- 
Table 2: Glucose and cAMP stimulation modulates the expression pattern of genes coding for AP-I components

\begin{tabular}{cccc}
\hline gene & \multicolumn{2}{c}{ mean of microarray signal } & fold-change \\
\cline { 2 - 3 } & control & stimulated & \\
c-fos & 107 & $\mid$ I' 16 I & $10.8^{*}$ \\
fos $B$ & 6 & 60 & $10.7^{*}$ \\
fra-I & 5 & 27 & 5.3 \\
fra-2 & 71 & 458 & $7.0^{*}$ \\
c-jun & 249 & 205 & -1.2 \\
junB & 59 & 275 & $4.6^{*}$ \\
junD & 811 & 647 & -1.2 \\
\hline
\end{tabular}

* significantly and consistently regulated IEGs

cose and cAMP still further stimulated the AP-1 reporter expression significantly (Figure 5B).

Further experiments were performed to determine whether the increased transcriptional activation by AP-1 could be explained by the induction of Fos genes. Min6 cells were co-transfected with pAP-1-luc and expression vectors for c-fos and c-jun. At constant levels of the c-jun vector, increasing amounts of transfected c-fos vector led to a gradual increase in reporter gene expression (Figure 5C). Consistently, Fos/Jun hetero-dimers transactivate more efficiently than Jun/Jun homo-dimers (see Additional file 5). Thus, the accumulation of c-fos gene product is sufficient to enhance transcription of AP-1 regulated genes.

In addition, we used A-FOS (a dominant negative form of AP-1) to block endogenous AP-1 transcription factor [22]. Results demonstrate that endogenous AP-1 mediates the transcriptional activation of the AP-1 reporter during stimulation with glucose and cAMP (Figure 5D). As control, we used A-C/EBP (a dominant negative form of C/ EBP transcription factor, structurally but not functionally similar to AP-1) which did not alter AP-1 reporter transcription neither in basal nor in stimulated conditions.

We then determined if the transcriptional induction of endogenous c-fos by glucose and cAMP would effectively change the composition of DNA binding AP-1 complex. Min6 cells were stimulated with glucose and glucagonlike peptide-1 (GLP-1), a physiologically active glucoincretin hormone which raises cAMP in beta cells [1]. Upon stimulation, c-fos mRNA induction was followed by a marked increase in nuclear c-FOS protein, as seen by western blot analysis of nuclear extracts (Figure 5E), as well as by immunocytochemistry (not shown). As a result, glucose-induced FOS protein formed functional AP-1 complexes (Figure 5F and 5G). This was shown by ELISA quantification of the components of AP-1 complexes binding to solid phase linked double stranded DNA with the specific AP-1 consensus sequence. The strong correla-
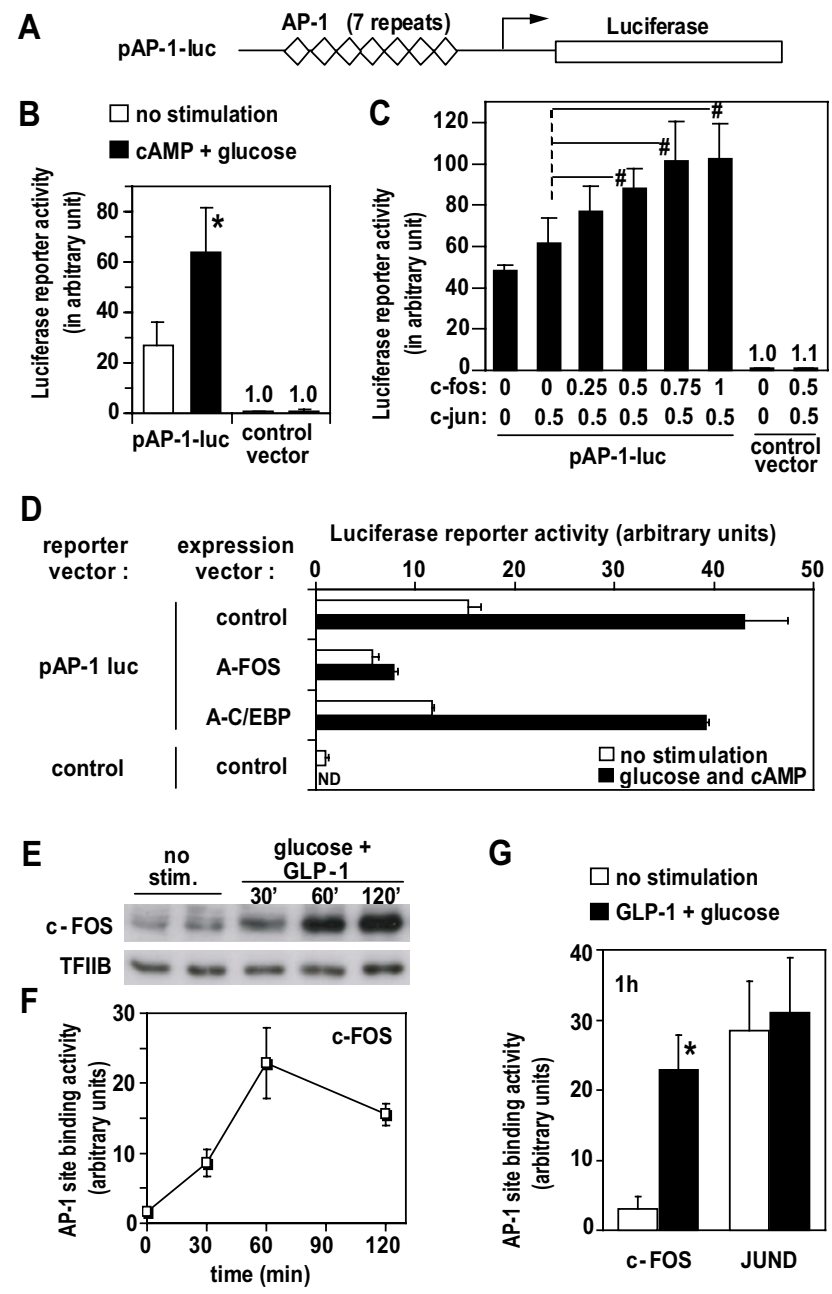

Figure 5

Glucose and CAMP regulate transcriptional activation by AP-I through induction of AP-I component expression. A) Schematic representation of PAP-I-luc reporter. B) Min6 cells were transfected with pAP-I-luc (or control vector) and maintained at low glucose before stimulation with glucose $(10 \mathrm{mM})$ and cpt-cAMP $(0.2 \mathrm{mM})$ for 6 hours. C) Cells were transfected with AP-I reporter (or control vector) and indicated quantity (in $\mu \mathrm{g}$ ) of expression vector for c-fos and c-jun. D) PAP-I reporter vector was cotransfected with either A-FOS (a c-FOS dominant negative form), empty vector (control) or A-C/EBP as additional control (dominant negative form of C/EBP, a transcription factor structurally related to c-FOS). Stimulations were performed as under B. E,F,G) Min6 cells cultured at low glucose were stimulated with high glucose (10 mM) and GLP-I (I0 nM) for indicated period of time. Nuclear extracts were analyzed by western (E). Specific binding of c-FOS and JUND to AP- I sequence was measured in nuclear extracts with an ELISAlike assay $(F, G)$. E, F) representative of two repeated experiments. \#, $\mathrm{p}<0.05$ vs c-Jun alone $(\mathrm{n}=3)$; *, $\mathrm{p}<0.0 \mathrm{I}(\mathrm{n}=4)$, by Student T-test. Error bars: s.d.; ND: not determined. 
tion between accumulation of FOS in nuclear extracts and its DNA binding activity indicates that newly synthesized FOS protein is efficiently recruited to DNA-binding AP-1 complexes (Figure 5E versus 5F). In contrast to c-FOS, and accordingly to a constant level of expression, JUND in functional AP-1 complexes remained unchanged (Figure $5 G)$.

The data in Figure 5 show that after glucose and cAMP induction of fos- and jun-like IEGs, the newly synthesized components are recruited to DNA binding AP-1 complexes, notably shifting their composition to Fos/Jun hetero-dimers which are more potent trans-activators than the constitutive Jun/Jun homo-dimers. Qualitative and quantitative changes in the AP- 1 complex may explain the increased expression of a large number $(14 \%)$ of glucose up-regulated target genes. This mechanism involves transcriptional induction of IEG and illustrates how IEGs and their downstream targets are linked.

\section{AP-I regulates the transcription of the target gene sulfiredoxin (srxn I/npn3)}

Having demonstrated that glucose and cAMP can activate AP-1 transcription factor, we pursued our investigations to identify which specific targets are effectively regulated by AP-1. A candidate approach was undertaken. The most strongly induced target gene in our system was sulfiredoxin

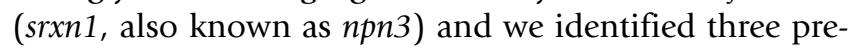
dicted AP-1 sites in its promoter; located 96, respectively 81 and 39 base pairs (bp) upstream of the transcriptional start site. Srxn1 promoter regions from different sizes were then cloned in front of a luciferase reporter gene and these constructs were transfected in Min6 cells. Results of this approach show that a narrow region of 81 bp containing the three AP-1 sites is both sufficient and necessary to srxn1 gene transcription in basal and stimulated conditions (Figure 6A). Co-transfection with the A-FOS dominant negative form of AP-1 impaired basal level of $\operatorname{srxn} 1$ reporter transcription and abolished stimuli responsiveness, indicating that AP-1 was necessary for these effects (Figure 6B). In addition, ectopic expression of c-Fos was sufficient to stimulate $\operatorname{srxn} 1$ reporter transcription (Figure 6C).

Finally, we established stably transfected Min6 cell lines expressing A-FOS as well as control constructs. The down regulation of AP-1 function in these stable clones was confirmed by assessing the transcriptional activation of a transiently transfected pAP-1-luc reporter (Additional file $6)$. The expression levels of endogenous $\operatorname{srxn} 1$ was then evaluated by quantitative RT-PCR (Figure 6D). While junD mRNA levels (control) were constant among the different clones, both basal and stimulated srxn1 mRNA levels were reduced in A-FOS clones. These effects were not due to a defective stimuli-responsiveness in A-FOS clones
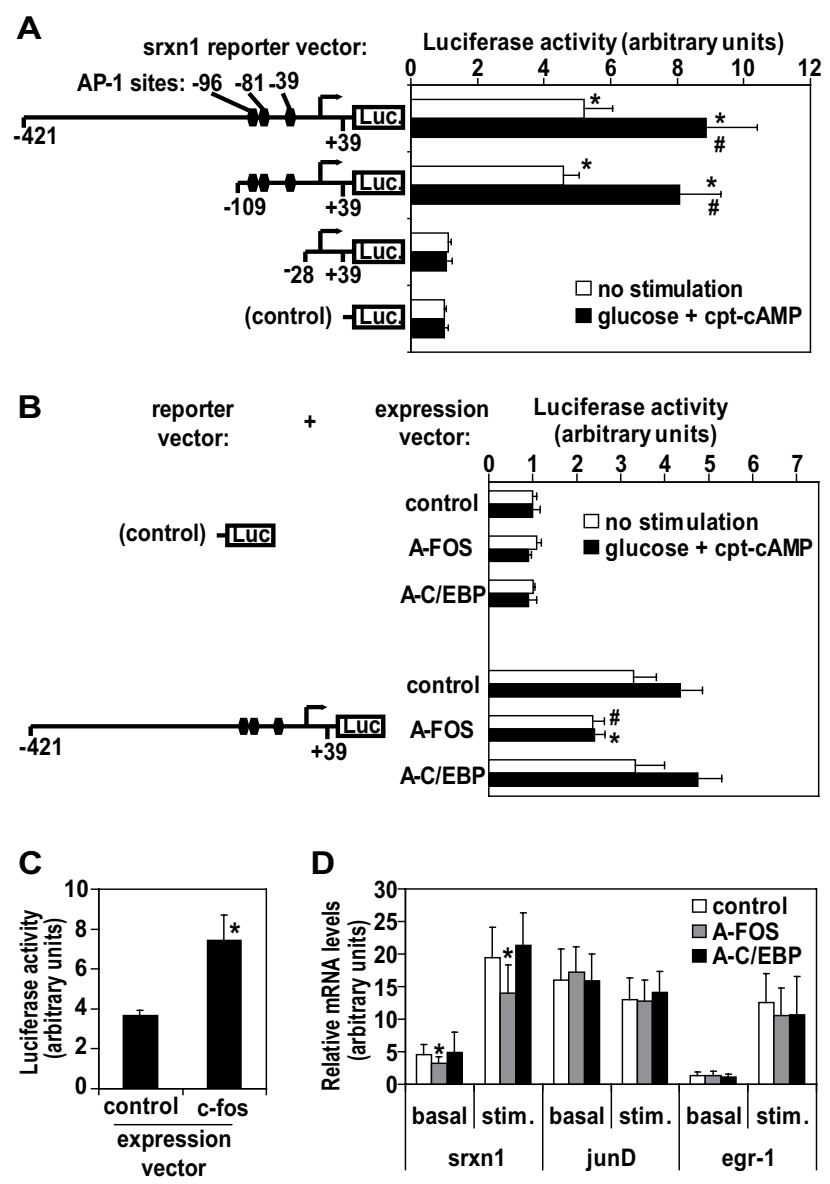

\section{Figure 6}

Srxn I is a transcriptional target of AP-I. A) Depicted srxn I reporter constructs were transfected in Min6 cells. Results as means of four independent experiments, with s.d. as error bars. *, $p<0.01$ vs control; \#, $p<0.0$ I vs corresponding non-stimulated condition, by Student T-test. B) Depicted srxnI reporter constructs were co-transfected respectively with A-FOS, A-C/EBP, or a control expression vector. Results as means of four independent experiments, with s.d. as error bars. *, \#, $p<0.0$ I, respectively $p<0.05$ vs control expression vector, by Student T-test. For A) and B), stimulations were performed with $0.2 \mathrm{mM}$ cpt-cAMP and 10 $\mathrm{mM}$ glucose for 6 hours. C) srxn I-42I/+39pGL3 reporter was cotransfected with c-fos expression vector (as in Figure 5). Results as means of four independent experiments, with s.d. as error bars. *, $p<0.01$ vs control expression vector, by Student T-test. D) mRNA levels for srxn I, junD and egr-I were quantified by RT-PCR in Min6 clones stably transfected with A-FOS, control expression vector and A-C/EBP respectively. Stimulations were performed with $0.2 \mathrm{mM}$ cpt-cAMP and $10 \mathrm{mM}$ glucose for four hours. Four different cell preparations were analyzed for each of at least three clones in each category. Results were pooled and expressed as mean of relative mRNA levels (arbitrary units) with s.d. as error bars. *, $p<0.00$ I vs control, by Student T-test. 
since egr-1 IEG responded normally. In conclusion, data in Figure 6 show that $\operatorname{srxn} 1$ is a downstream transcriptional target of AP-1.

\section{AP-I and its target srnxI are regulated by metabolic stimuli in primary pancreatic islets}

Because some aspects of signaling in cell lines (like Min6) may be altered by the transformation or the long term maintenance in culture, we evaluated if our results could be consistently reproduced in primary cells from isolated islets.

Firstly, we evaluated the effects of metabolic stimuli on expression of several IEG mRNA in isolated rat primary islets (Figure 7). Glucose synergized with cpt-cAMP or with GLP-1 to induce c-fos, fra-1, fra-2 and junB, while cjun and junD remained unaffected by these stimuli (Figure $7 \mathrm{~A}$ and $7 \mathrm{~B}$ ). The pattern is identical to what was observed in Min6 (Table 2). Furthermore, we observed induction of egr-1 and nur77 (two IEGs encoding transcription factors which were induced in Min6), indicating that the parallel between Min6 and primary islets is not limited to AP-1. Interestingly, dose-dependency experiments indicated that maximal stimulation of IEGs was reached in presence of GLP-1 and within a physiological ( 5 to $15 \mathrm{mM}$ ) range of glucose concentrations (Figure 7C). Noteworthy, we obtained similar synergistic activation of IEGs with isolated (FACS sorted) beta cells stimulated with glucose and GLP-1 (Additional file 7), respectively glucose and cptCAMP (data not shown). Without excluding induction of IEGs in other islet cell types (like glucagon-secreting cells or somatostatin-secreting cells), these data indicate that IEG mRNA accumulates in response to metabolic stimuli in primary pancreatic beta cells.

Secondly, we investigated whether changes in IEG mRNA levels were effectively followed by changes in protein levels. c-FOS expression was thus assessed by immunocyto-

\section{A}

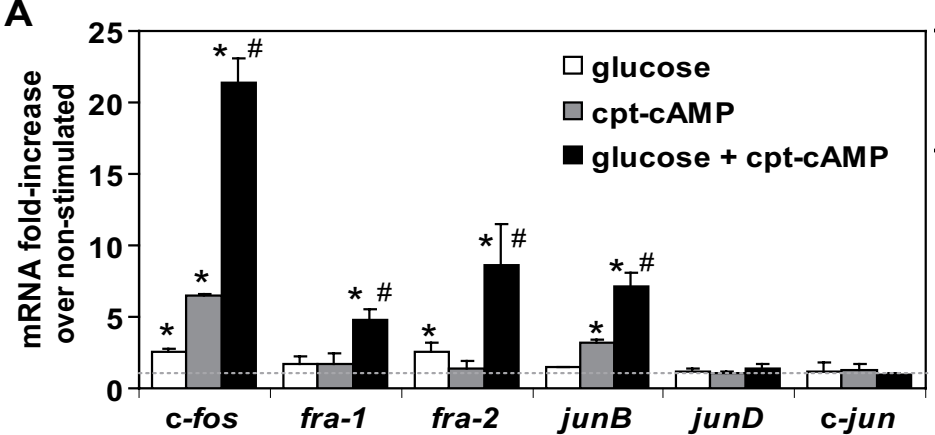

B

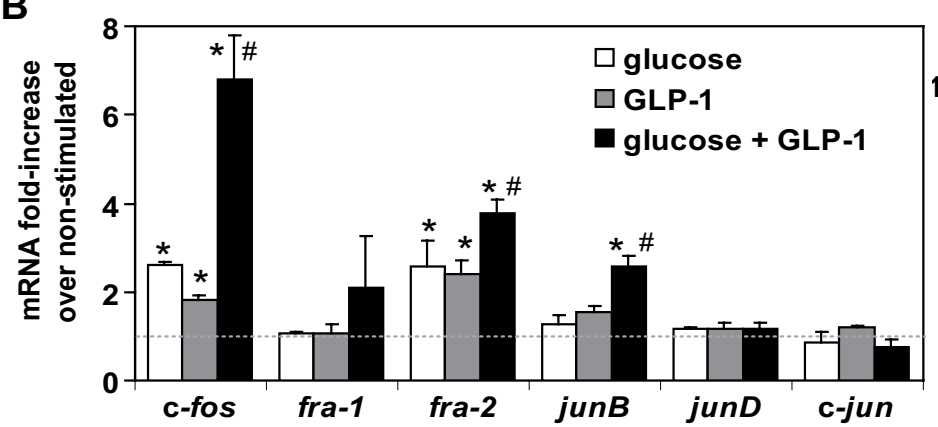

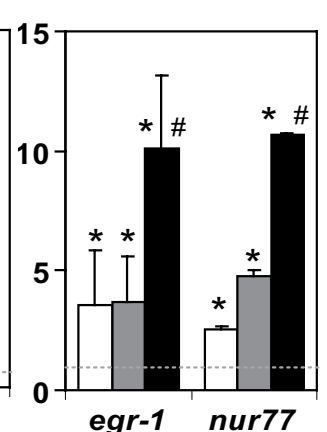

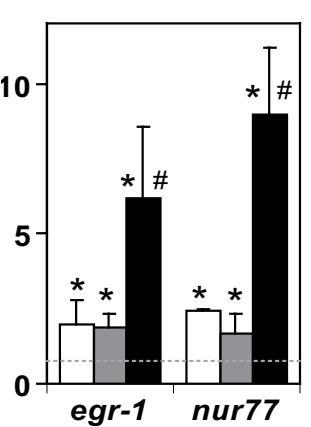

C
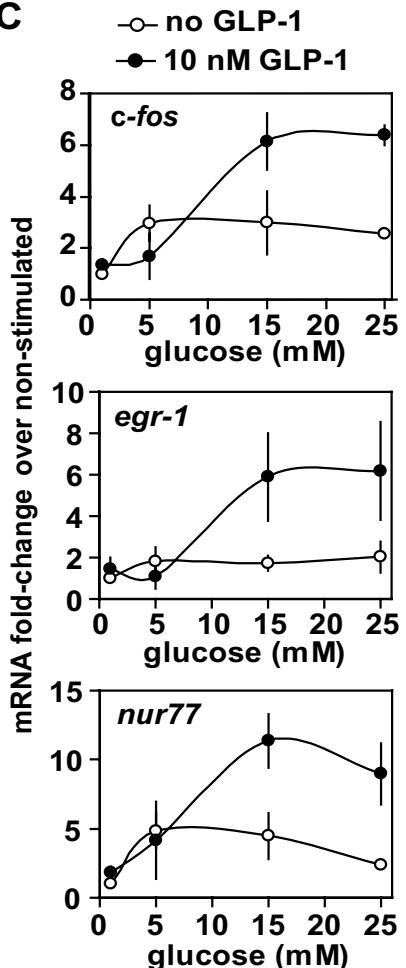

Figure 7

Induction of IEGs by metabolic stimuli in isolated rat islets. Rat islets were isolated, cultured and serum deprived at reduced glucose concentration (I mM) for 20 hours. Stimulation was done for one hour with $0.2 \mathrm{mM} \mathrm{cpt}-\mathrm{cAMP}$ and/or $25 \mathrm{mM}$ glucose (A); or with $10 \mathrm{nM}$ GLP-I and/or $25 \mathrm{mM}$ glucose (B). mRNA levels for mentioned genes were quantified in triplicate by real-time RT-PCR, normalized with reference to I8S rRNA, and are shown as fold-increase over non-stimulated controls.

Shown are the means of values obtained for three $(A)$ or two $(B)$ independent experiments (error bars = s.d.). Student T-tests were used for statistical analysis; ${ }^{*} p<0.05$ vs non-stimulated; \# $p<0.05$ vs single stimulus conditions. C) Effect of various glucose concentrations on the induction level of IEG expression (after one hour stimulation). Results as mean of at least two independent experiments (s.d. as error bars). 


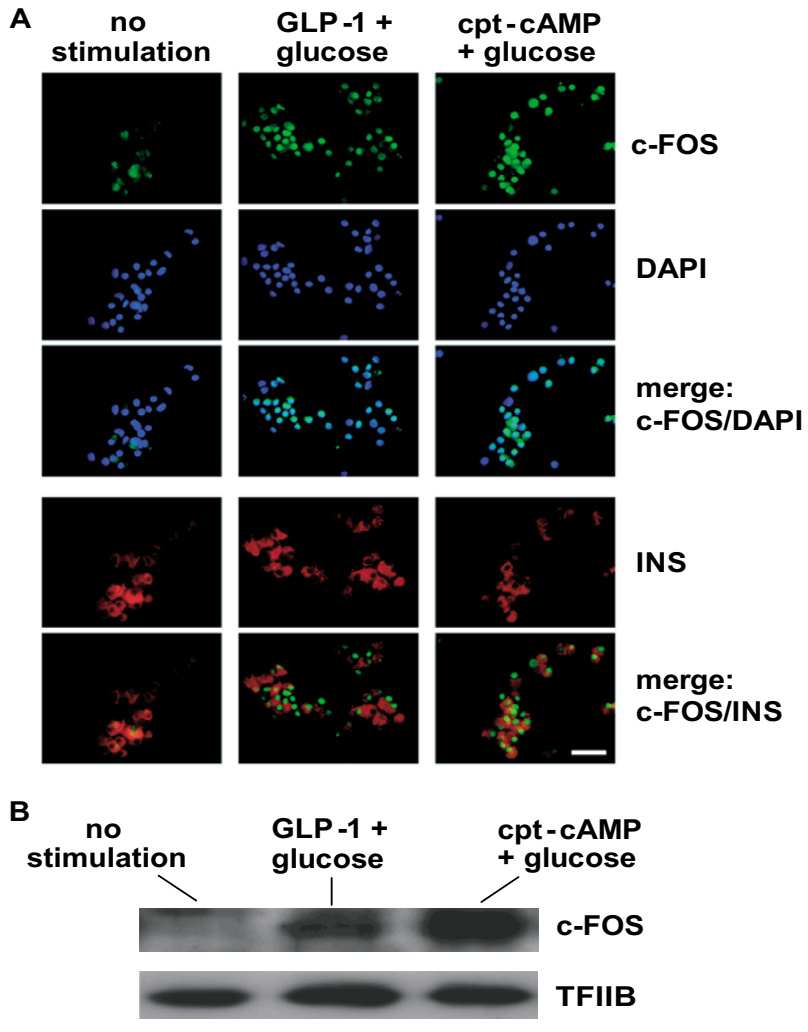

Figure 8

Accumulation of c-FOS protein in the nuclei of primary beta cells upon metabolic stimulations. A) Islets were isolated, trypsin digested, cultured and serum deprived at low glucose concentration ( $1 \mathrm{mM}$ ) for 20 hours. After 60 minutes of co-stimulation with $10 \mathrm{nM} \mathrm{GLP-I}$ and $15 \mathrm{mM}$ glucose or $0.2 \mathrm{mM}$ cpt-cAMP and I $5 \mathrm{mM}$ glucose, islets (50- 100 per condition) were fixed and analyzed by immunofluorescence staining of c-FOS (green) and of insulin (INS, red); nuclei were stained with the DNA reactive DAPI dye (violet). Fluorescence images shown separately for each dye or merged (c-FOS/DAPI; c-FOS/INS) are representative of three different experiments. Bar: $50 \mu \mathrm{m}$. B) Islets were isolated, maintained and serum deprived at low glucose concentration (I mM) for 20 hours, prior to co-stimulation with 10 nM GLP-I and $15 \mathrm{mM}$ glucose or $0.2 \mathrm{mM}$ cpt-cAMP and 15 mM glucose. After 90 minutes of stimulation, islets ( 800 per condition) were trypsin digested, nuclear extracts were prepared and c-FOS expression analyzed by western blotting. TFIIB was used as loading control.

chemistry in dispersed islets (Figure 8A) and by western blot analysis in nuclear extracts prepared from intact islets (Figure 8B). Under low glucose conditions, immunofluorescence staining of dispersed islets produced only a faint background signal for c-FOS. Upon co-stimulation by glucose and GLP-1 or cpt-cAMP, expression of c-FOS became strongly apparent. c-FOS protein was mainly detected in nuclei, co-localizing with DAPI staining for DNA. Co-

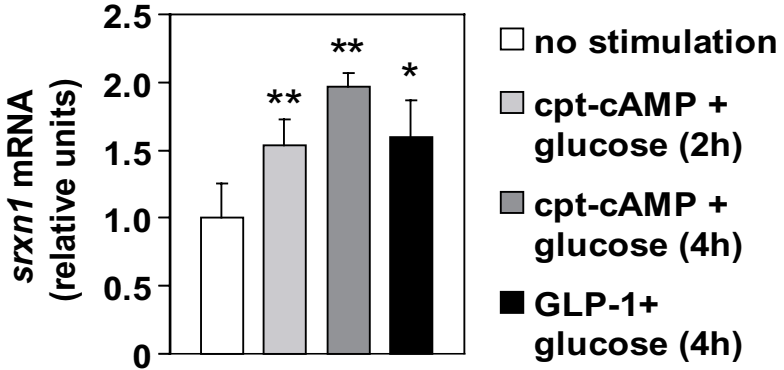

Figure 9

Induction of srxn I expression by metabolic stimuli in isolated rat islets. Rat islets were isolated, cultured, and serum deprived at reduced glucose concentration (I mM) for 20 hours. Stimulation was done for indicated period of time with high glucose $(25 \mathrm{mM})$ plus cPt-cAMP $(0.2 \mathrm{mM})$ or GLP-I (I0 nM). Transcript levels of the AP-I target gene srxn I were quantified by real-time RT-PCR, normalized with reference to I8S rRNA, and shown as relative values. Shown are the means of values obtained for at least three experiments. Student T-tests were used for statistical analysis; ${ }^{*} p<0.05$ vs non-stimulated; $* * p<0.01$ vs non-stimulated.

staining for insulin showed that nuclear c-FOS protein was found in beta cells. Western blot analysis confirmed the accumulation of c-FOS protein in the nucleus of primary islet cells. As depicted in Figure 8B, c-FOS protein levels were nearly undetectable in islets maintained at low glucose concentrations. Within 90 minutes of stimulation by GLP-1 and elevated glucose, c-FOS became prominently present in the nuclear extracts. Using cpt-cAMP as co-stimulator with glucose led to a further increase in the c-FOS signal on the western blots. Quantitatively, these data on nuclear c-FOS protein corroborate observations made at the mRNA level, with a strong effect of cpt-cAMP and a more moderate effect of GLP-1 (Figure 8B), and are similar to observations made in Min6 cells (Figure 5E, Additional file 8 and data not shown).

Thirdly, we evaluated whether AP-1 regulation by metabolic stimuli could be functional in islets. To that purpose, expression levels of the newly identified AP-1 target gene srxn 1 were quantified by RT-PCR in isolated rat islets. As in Min6 cells, co-stimulation with glucose and cptcAMP, or glucose and GLP-1, induced significant accumulation of $\operatorname{srxn} 1$ mRNA (Figure 9).

Altogether, data in Figures 7, 8, and 9 show that a functional AP-1 regulation occurs in primary beta cells in response to metabolic stimuli. This shows the potential physiological relevance of the observations made in Min6, and emphasizes the interest of the dataset obtained with our screening approach in this cell line model. 


\section{Discussion}

The present study provides a comprehensive view on the changes in gene transcription that occur within the first hours after pancreatic beta cell stimulation with glucose plus CAMP or incretin hormones. Induced IEGs and their downstream targets were identified on a genomic scale. Both IEGs and targets code for proteins involved in a large spectrum of cellular functions, including those tightly related to beta cell physiology, suggesting that these inductions may mediate long term cellular adaptation. Statistics on the response elements in target promoters pointed towards a predominant role of AP-1 composed of IEG products of the fos and jun families. The mediator role of AP-1 for the induction of a newly identified specific target $(\operatorname{srxn} 1)$ was substantiated by expressing loss- and gainof-function mutants of c-fos.

\section{Indirect mechanisms of gene regulation}

The metabolic state of a pancreatic beta cell is translated readily and without delay into insulin secretion which is adjusted within minutes to altered glucose stimulation. Such direct translation of metabolic state into regulated expression is not possible for genes which change their expression over much longer time frames (hours, days). The transcriptional regulation of IEGs coding for transcription factors according to beta cell metabolic activity provides a mechanism by which target gene transcription can be controlled over longer time frames. Increasing or decreasing the presence of such transcription factors on the promoters of target gene will affect the rate of transcription. Here we illustrate this mechanism with the AP1 transcription factor, the importance of which is indicated by the over-representation of AP-1 binding sites in up-regulated target promoters. By modulating the pattern of expression of the different AP- 1 complex components (notably through the strong induction of c-fos), glucose and CAMP shift the composition of AP-1 dimer. The transcriptional induction of c-fos by glucose and cAMP relies on the activation of CaMkinase II and PKA which converge to regulate cis-elements in its promoter (Susini et al., 2000); in addition insulin signaling may also be involved, as reported in other cell systems (Griffiths et al., 1998). The shift in AP-1 composition increases transcriptional activation of an AP-1 reporter gene, as well as at least one endogenous AP-1 target ( $\operatorname{srxn} 1)$, showing that it has the potential to affect numerous genes with an AP-1 binding sequence in their promoters. Furthermore, the shift in AP1 composition (leading to a change in its transactivation potential), as well as the up-regulation of srnx1 are observed in cultured intact islets. Together with the observation of IEGs induction in vivo [10], this illustrates the physiological relevance of our observations in the Min6 cell line.
The AP-1 example illustrate the complexity of indirect regulation, since this transcription factor exists in many combinations of JUN and FOS like proteins, some of which are constitutive and some of which can be post-translationally modified. This gives rise to a whole repertoire of AP-1 complexes with differential selectivity for distinct AP-1 binding sites, varying trans-activation potential, and differential interactions with other transcription factors acting on the same promoter [23-25].

It should be mentioned that transcriptional activation, as proposed here with the example of AP-1, is not the only possible mechanism able to explain changes in mRNA levels (as those quantified by microarrays and RT-PCR); IEG products regulating target mRNA levels may also be proteins involved in the control of mRNA degradation or in the upstream signaling pathways that modulate the activity of transcription factors and regulators of mRNA stability.

\section{Limitations}

IEGs are defined as genes induced without the need for protein de novo synthesis. IEGs are thus identified with the use of protein synthesis inhibitors like CHX (cycloheximide).

Results obtained with CHX have to be considered with some caution. In addition to blocking protein synthesis, CHX may also affect RNA and protein stability as well as signaling pathways $[26,27]$. Design and interpretation of our microarray experiments aimed to reduce the impact of the non-specific effects of CHX to a minimum. We considered in our gene lists only those genes which responded to stimulation when tested in the absence of CHX; thus, CHX data were only used to separate IEGs from targets within the list of stimuli-responsive genes. Furthermore, in the experiments where cells were stimulated in the presence of CHX, induction was assessed against the CHX control conditions. Therefore, in our analysis, side effects of $\mathrm{CHX}$ could have caused mis-labeling of responding genes as IEGs or targets under very particular circumstances. As these appear relatively unlikely, we are confident that the large majority of genes are correctly listed. Indeed, the detailed induction kinetic of several IEGs and targets genes selected from these lists show distinct temporal patterns of induction; the induction of all targets ( 7 genes analyzed) was delayed compared to the rapid induction of the IEGs (4 genes analyzed) [18]. Moreover, in the present study, we were able to verify the predictions about AP-1 based on the in silico target gene promoter analysis. Hence, in spite of the limitations linked to using CHX, our microarray data represent a valid starting point to further advance our understanding of the transcriptional response of beta cells to metabolic signals. 
The cellular function of glucose and cAMP regulated genes Glucose and cAMP responsive genes form large clusters functionally involved in secretion, metabolism, and beta cell mass control (proliferation/apoptosis). Regulation according to the metabolic state of such specific pancreatic beta cell functions is in agreement with previous studies $[8,28]$. However, a completely novel and unexpected finding is that genes involved in DNA damage checkpoint/repair represent a large down-regulated cluster. This is consistent with the down-regulation of key transcription factors governing this pathway ( $p 53$, foxo3) and some downstream apoptosis effectors like $b b c 3$, also known as puma (Additional file 1) [29-31]. This raises intriguing questions about the possible implication of DNA damage pathway in the control of beta cell survival by glucose and will require further investigations.

Srxn1 gene product sulfiredoxin reactivates peroxiredoxins $\left(\mathrm{H}_{2} \mathrm{O}_{2}\right.$ scavenging enzymes) by catalyzing the reduction of sulfinic acids formed on peroxiredoxins following exposure to excessive levels of $\mathrm{H}_{2} \mathrm{O}_{2}$ [32]. Recently, sulfiredoxin was also shown to be involved in the reversal of protein glutathionylation [33]. Thus, sulfiredoxin is emerging as an important component in the cellular redox signaling/control systems. To our knowledge, our study provides the first report on the mechanisms of srxn1 gene transcriptional regulation in mammals. Regulating the amount of sulfiredoxin in function of cell metabolic stimulation (which is known to be associated with oxidative stress and generation of $\mathrm{H}_{2} \mathrm{O}_{2}$ in beta cells [34]) con-

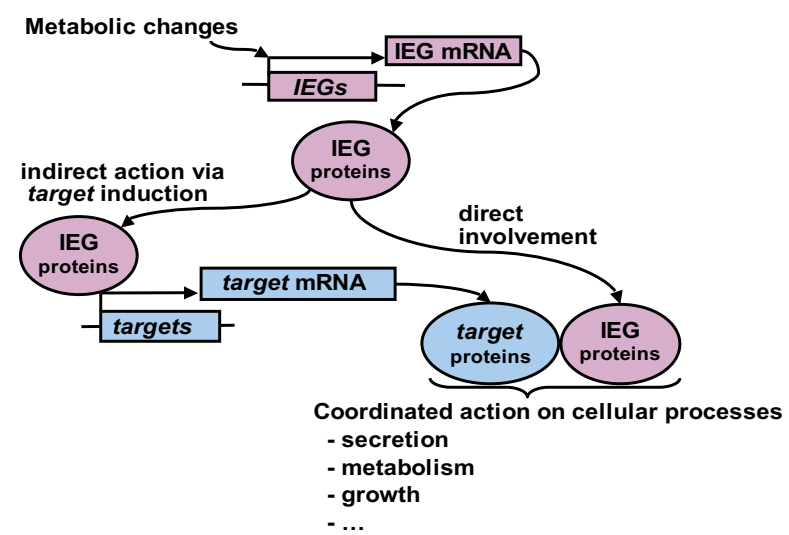

Figure 10

Cellular adaptation to physiologically relevant stimuli occurring via a combination of direct and indirect modes of transcriptional control. IEG products have two modes of action in the cellular adaptation to metabolic signals. Some IEG products act indirectly by controlling transcription of target genes. Other IEG products are involved directly in regulated cellular processes. A coherent adaptation of these processes requires the combined action of both IEG and target gene products. stitutes a feedback response susceptible to attenuate $\mathrm{H}_{2} \mathrm{O}_{2}$ effects and signaling.

\section{Conclusion}

The present study sheds light on the mechanisms by which beta cell adapts its transcriptional program in response to metabolic and hormonal stimuli known to control secretion of insulin in the short term and proliferation, cell survival, and responsiveness in the long term. Our findings on the role of the AP-1 transcription factor as a mediator for the induction of srxn1 (sulfiredoxin) illustrate that IEG transcription factors may effectively relay metabolic signals to regulate transcription of target genes in beta cells.

The large number of induced target genes and the wide array of cellular functions concerned suggest that indirect mechanisms of gene regulation (through IEG induction) likely play a substantial role in beta cell adaptation. However, the observation that a significant portion of IEGs codes for proteins that are directly involved in adapted cellular functions shows that direct induction of IEGs transcription complements the indirect mode of gene regulation (Figure 10).

\section{Methods \\ Chemicals}

Cycloheximide (CHX), chlorophenylthio-cAMP (cptCAMP) and glucagon-like peptide-1 (GLP-1) (7-37, human) were purchased from Sigma (Buchs, Switzerland).

\section{Min6 cell culture and incubations}

Min6 B1 cells [35] (generously provided by Dr. Philippe Halban, Dept of Development and Medical Genetics, Medical faculty of Geneva University) (passage 15-25) were cultured in DMEM supplemented with $15 \%$ fetal calf serum, $25 \mathrm{mM}$ glucose, $71 \mu \mathrm{M}$ 2-mercaptoethanol, 100 units/ml penicillin, $100 \mu \mathrm{g} / \mathrm{ml}$ streptomycin and $50 \mu \mathrm{g} /$ $\mathrm{ml}$ gentamycin. Medium was changed to low glucose medium (same as above with $1 \%$ FCS and $1 \mathrm{mM}$ glucose) 20 hours before a 4 hour stimulation with glucose (10 $\mathrm{mM})$ and cpt-cAMP $(0.2 \mathrm{mM})$. When used, CHX (5 $\mu \mathrm{g} /$ $\mathrm{ml}$ ) was added $45^{\prime}$ prior to stimulation.

\section{Islet and primary beta cell isolation, culture and incubations}

7-Week-old male Wistar rats $(\sim 250 \mathrm{~g})$ were purchased from Elevage Janvier (Le Genest-St-Isle, France). Pancreatic islets were isolated by collagenase digestion, handpicked, and maintained in $11.1 \mathrm{mM}$ glucose/RPMI 1640 (Invitrogen) supplemented with $10 \%$ fetal calf serum (Amimed, BioConcept Allschwil, Switzerland), 100 units/ $\mathrm{ml}$ penicillin, $100 \mu \mathrm{g} / \mathrm{ml}$ streptomycin and $50 \mu \mathrm{g} / \mathrm{ml}$ gentamycin (Sigma). 
For the induction experiments, islets were maintained for 48 hours after isolation and serum deprived for 20 hours in low glucose medium ( $1 \mathrm{mM}$ glucose RPMI 1640 (Invitrogen), 0.1\% BSA and same antibiotics as above). Consecutively, islets were stimulated with glucose, GLP-1 or cptcAMP as detailed in the respective figure legends.

For beta cell purification, islets were trypsin digested and FACS sorted as earlier described [36]. Beta cells were maintained in $11.1 \mathrm{mM}$ glucose/Dulbecco's modified Eagle's medium (DMEM) (Invitrogen) supplemented with $10 \%$ fetal calf serum and same antibiotics as above, for five days to permit re-aggregation in small clusters. 20 hours before stimulation cells were serum deprived in low glucose medium (1 mM glucose/DMEM supplemented with $0.1 \%$ BSA, and same antibiotics as above).

\section{RNA preparation and microarray analysis}

All the stimulations were performed at the same time (in parallel), with an unique batch of cells plated at uniform confluence. For each experimental condition, transcript profiles were established for three different preparations of total RNA made using RNeasy Micro Kit (Qiagen). Labeled cRNA synthesis, hybridization to the arrays and scanning were essentially performed as earlier described [37]. Affymetrix Mouse Genome 4302.0 oligonucleotide array (containing probe features for 45'101 transcripts) were used. Fluorescence signals from the arrays were analyzed with Affymetrix software GCOS for normalization and calculation of gene-expression values [38,39].

\section{Criteria to define differentially expressed transcripts}

The definition of differentially expressed transcripts between two experimental conditions was based on three criteria: concordance between replicates, statistical significance and fold-change cutoff. The strategy to evaluate the concordance of an effect in two different experimental conditions was the following: each replicate of one condition was compared to each replicate of the other, resulting in 9 pairwise comparisons. Transcripts were considered as differentially expressed if their levels changed in the same direction in at least 7/9 comparisons. The second criterion was a p value by Welch $\mathrm{T}$ test below 0.05 when comparing signal values in two experimental conditions. Finally, the third criterion was a minimal fold-change values of 1.5.

\section{Criteria to delineate IEGs and targets}

We considered genes that were differentially expressed in control (no stimulation) vs stimulated (glucose + cAMP) condition; these representing glucose and CAMP regulated genes. We divided this list of genes into two lists: IEGs and targets. To do so, different criteria were used.

\section{Main criterion}

The main criterion was the responsiveness in presence of $\mathrm{CHX}$. From the initial list of regulated genes, we considered genes that were differentially expressed in control+CHX (no stimulation in presence of CHX) vs stimulated $+\mathrm{CHX}$ (glucose + cAMP in presence of CHX) conditions; these represent IEGs (genes that respond to glucose and cAMP in presence of $\mathrm{CHX}$ ). The rest of the genes (that were initially found to respond to glucose and cAMP but were not regulated in presence of $\mathrm{CHX}$ ) were defined as targets. This single criterion is very stringent for the definition of IEGs, but may lead, on the other hand, to a high level of false positive in the target category. This is particularly unsuitable, notably for the validity of target promoter sequence analysis. Thus it was necessary to introduce more criteria to increase the quality of target list.

\section{Criteria to increase target list quality (secondary criteria)}

Some genes responded to $\mathrm{CHX}$ alone. If CHX produces more effect than glucose, it can mask the effect of glucose in presence of CHX (saturating regulation by CHX). For this reason, IEGs can be falsely considered as targets with the main criterion (here-above). Thus we excluded from up-regulated target gene list, the genes for which expression was higher in either control $+\mathrm{CHX}$ or stimulated $+\mathrm{CHX}$ conditions compared to the stimulated condition. Similarly, we excluded from down-regulated target gene list, the genes for which expression was lower in either control $+\mathrm{CHX}$ or stimulated $+\mathrm{CHX}$ conditions compared to the stimulated condition. Finally, we excluded from the target list, genes for which the mean signal difference between stimulated $+\mathrm{CHX}$ and control represented more than $25 \%$ of the signal in the stimulated condition. Genes excluded from the target list by these secondary criteria were attributed to the IEG list.

\section{Quantitative real-time RT-PCR}

Each total RNA sample was reverse-transcribed in triplicate with random hexamers as primers and Omniscript reverse transcriptase (Qiagen). Quantitative real-time PCR were performed with the SYBR Green system as described in Brun et al. [40]. Primers were provided by Microsynth (Balgach, Switzerland) and their sequences are presented in Additional file 9. For normalization, 18S RNA was quantified in each sample using $0.3 \times 18$ S rRNA Predeveloped Assay Reagent and $1 \times$ TaqMan ${ }^{\circledR}$ Universal PCR Master Mix (Applied Biosystems).

PCR amplicons were quality controlled and all displayed a single homogeneous melting curve as well as the correct size on $2 \%$ agarose gels. A cDNA serial dilution standard curve was added to the microtiter plate of each amplification reaction to calibrate each relative quantification in function of PCR amplification efficiency. 


\section{Promoter analysis}

TFExplorer predicted regulatory element database [20] was used to map regulatory elements in promoters (from $-1000 \mathrm{bp}$ to $+300 \mathrm{bp}$ from transcription start site) (accessed on June 17th 2005 [41]). We analyzed promoters of target genes (132 up-regulated gene promoters, 239 down-regulated gene promoters) and of two control sets of promoters from genes randomly chosen among those present (detectable in Min6 cells, 1188 promoters) or those absent (undetectable in Min6 cells, 1164 promoters). For each promoter set (up-regulated targets, downregulated targets and controls) we counted the number of promoters (Hit numbers) in which a given regulatory element was present (at least once). We calculated the frequencies for any given regulatory element within each set, and evaluated the statistical significance of the difference to the control sets by Fisher exact test.

\section{Nuclear extract preparation and DNA binding assay}

Nuclear protein extracts were prepared according to the protocol of Schreiber et al.[42]. The detection of c-FOS and JUND specific binding to AP-1 site was made with the ELISA-like TransFactor Kit Inflammation II (BD Biosciences AG, Switzerland) according to supplier instructions except that the colorimetric detection step was replaced by a chemiluminescent one. Briefly, after initial blocking, 12 $\mu \mathrm{g}$ of nuclear extracts were incubated 60 minutes in AP-1 or STAT consensus oligo coated 96-well plates. Plates were then washed three times, incubated 60 minutes with primary antibodies (anti-c-FOS or anti-JUND), washed three times and incubated 30 minutes with HRPO-anti-rabbitIgG secondary antibody (Transduction Laboratories) (1:10'000). After final four washes, $100 \mu \mathrm{l}$ of $1 \times$ ECL HRP substrate (Cell Signaling Technology) were added to each well and light emission measured three times with a FLUOStar OPTIMA (BMG LABTECH GmbH). Binding to coated STAT oligo and competition with soluble AP-1 oligo were used to check binding specificity. Results were expressed in arbitrary units of DNA binding after normalization by values of no template controls (NTC) for each independent experiment.

\section{Srxn I reporter construction}

Srxn1 promoter regions of three different sizes $(-421 /+39$; $-109 /+39 ;-28 /+39$ from the transcriptional start site) were amplified by PCR. Primer were designed from sequences found in ENSEMBL database (entry: ENSMUST00000041500) with addition of 5' flanking residues to create restriction sites (Xhol for forward primers, HindIII for the reverse primer; allowing directional insertion). Three different forward primers were used srxn1421, AACTCGAGAGACAGCGCTGGGATCCAA; srxn1109, AACTCGAGGGCCTGAGTCACCACGCT; srxn1-28, AACTCGAGCGTCCATTGAGCGCATCG (Xhol site in bold). A single reverse primer was used srxn1+39: GAT-
TAAGCTTCTGACCTAGCTGCCCACTGCC (HindIII site in bold). PCR products were initially cloned into pGEMTeasy vector (Promega) using Takara mighty mix DNA ligation kit (Takara Bio Inc.) and sequentially restriction digested with HindIII and XhoI (Roche). Inserts of respective expected sizes were cloned into pGL3enhancer vector (Promega) that had been previously restriction digested with the same enzymes and treated with alkaline phosphatase (Roche). Construction sequences were verified by the Dye Terminator sequencing technique using Rvprimer3 (CTAGCAAAATAGGCTGTCCC) at the DNA sequencing facility of Geneva University Medical Center.

\section{Luciferase reporter analysis}

$0.5 \mu \mathrm{g}$ PathDetect ${ }^{\circledR}$ cis-Reporting System pAP-1-Luc or pCIS CK (negative control) plasmids (Stratagene Europe, Amsterdam Zuidoost, The Netherlands) were co-transfected with $0.5 \mu \mathrm{g}$ of Renilla luciferase plasmid (for normalization) (Promega, Luzern, Switzerland) using Lipofectamine 2000 reagent (Invitrogen) according to supplier's instructions. In the ectopic expression experiment, pMSCV-c-Fos (c-Fos expression vector) and/or pMSCV-c-JunFlag (c-Jun expression vector) [43] (both generously provided by Dr. Gerald Thiel, University of Saarland Medical Center, Germany) were cotransfected at various concentrations (see figure legends). Luciferase activity measurement was performed 24 hours after the transfection as previously described [14]. In stimulation experiments, cells were transfected with reporter vectors, maintained for 20 hours in culture medium, changed to low glucose medium for additional 20 hours, and stimulated for 6 hours with $10 \mathrm{mM}$ glucose and $0.2 \mathrm{mM}$ cptcAMP (in triplicate).

\section{AP-I loss-of-function experiments}

pCMV500 (control), pCMV500-A-FOS and pCMW500-AC/EBP (kind gift of Dr. Charles Vinson, National Cancer Institute, Laboratory of Metabolism, Bethesda, MD, USA) were used in transient co-transfection with reporter constructs or for establishment of stable transfectant Min6 clones. In the latter case, after transfection, $400 \mathrm{mg} / \mathrm{l} \mathrm{G} 418$ were added to culture medium for a selection period of one month. Clones were picked-up and grown in culture medium supplemented with $200 \mathrm{mg} / \mathrm{l} \mathrm{G} 418$. A decrease in AP-1 reporter was specifically found in A-FOS clones transiently transfected with pAP-1-luc (Additional file 6). At least three different clones for each construct were used in the experiments.

\section{Western blotting and immunocytochemistry}

Nuclear extracts $(15 \mu \mathrm{g})$ were resolved on SDS-PAGE (10\% gel) and subject to immunoblot analysis as earlier described [44]. Primary antibodies were rabbit anti-c-FOS (1:1'000, sc-52) and anti-TFIIB (1:10'000, sc-225) (Santa Cruz Biotechnology, Inc.). For immunofluorescence stud- 
ies, partially trypsin dispersed rat islets were cultivated and pre-incubated in low glucose RPMI 1640 medium as described above for intact islets. After stimulation, cells were subjected to cytospin on SuperFrost ${ }^{\oplus}$ Plus slides (Menzel GmbH and Co KG, Braunschweig, Germany) and fixed in $4 \%$ paraformaldehyde $\mathrm{pH} 7.0$ for 30 minutes at room temperature. After three PBS washes and two incubations with boiling $10 \mathrm{mM}$ citrate $\mathrm{pH} 6.0$ for two minutes, cells were permeabilized with $0.2 \%$ Triton PBS for 15 minutes. Primary antibody for c-FOS (rabbit anti-cFOS, 1:200, sc-52, Santa-Cruz Biotechnology) and mouse anti-insulin (1:1000, I-2018, Sigma) were diluted in $0.05 \%$ triton PBS and used for an overnight incubation. After three washes, cells were incubated one hour with secondary antibodies (alexa-488 labeled anti-rabbit-IgG and alexa-568 labeled anti-mouse-IgG (both 1:300; Molecular Probes)). After washings, cells were incubated three minutes in $5 \mathrm{mg} / \mathrm{ml}$ 4',6-Diamidino-2-phenylindol (DAPI), washed three times and mounted in Dakocytomation fluorescent mounting medium (DakoCytomation AG, Untermüli, Switzerland). Images were acquired with a Zeiss Axiocam Imaging System (Bioimaging Core Facility, Medical Faculty, Geneva University).

\section{Numbers of repeated experiments}

In the figure legends, $\mathrm{n}$ represents the number of repeated experiments. This corresponds to different cell preparations (in the case of islets, preparation from different rats).

\section{Authors' contributions}

DAG conceived the study, designed and performed the experiments, analyzed the results, and drafted the manuscript. TB participated in the experiments with rat islets and helped to draft the manuscript. BRG contributed to experiment design and helped to draft the manuscript. WS conceived the study, designed experiments, and drafted the manuscript. All authors read and approved the final manuscript.

\section{Accession number}

The microarray dataset has been submitted to Array Express database [45] under accession number E-TABM141.

\section{Additional material}

\section{Additional file 1}

Glucose and cAMP responsive IEGs and target genes. Table presenting the full list of glucose and cAMP responsive IEGs and target genes. Click here for file

[http://www.biomedcentral.com/content/supplementary/14712199-8-54-S1.xls]

\section{Additional file 2}

Validation of microarray results by RT-PCR. Table comparing the foldchange values obtained by microarray versus RT-PCR.

Click here for file

[http://www.biomedcentral.com/content/supplementary/1471-

2199-8-54-S2.pdf]

\section{Additional file 3}

Glucose and cAMP regulated genes involved in secretion. Table presenting a list of glucose and cAMP regulated genes involved in secretion. Click here for file

[http://www.biomedcentral.com/content/supplementary/14712199-8-54-S3.xls]

\section{Additional file 4}

Target promoter sequence analysis. Table presenting all the significantly over-. and under-represented regulatory elements.

Click here for file

[http://www.biomedcentral.com/content/supplementary/14712199-8-54-S4.pdf]

\section{Additional file 5}

Increased transactivation by Fos/Jun compared to Jun/Jun AP-1 dimer. Figure presenting the results of co-transfection experiments. Click here for file

[http://www.biomedcentral.com/content/supplementary/14712199-8-54-S5.pdf]

\section{Additional file 6}

Down-regulation of AP-1 activity in A-FOS stable clones. Figure presenting the results of transfection experiments.

Click here for file

[http://www.biomedcentral.com/content/supplementary/14712199-8-54-S6.pdf]

\section{Additional file 7}

Induction of IEGs in purified primary beta cells. Figure presenting the results of IEG transcript quantification in FACS-sorted primary beta cells. Click here for file

[http://www.biomedcentral.com/content/supplementary/14712199-8-54-S7.pdf]

\section{Additional file 8}

Accumulation of c-FOS protein in the nucleus of Min6 cells following stimulation. Figure presenting the results of Western blot and immunocytochemistry analyses.

Click here for file

[http://www.biomedcentral.com/content/supplementary/14712199-8-54-S8.pdf]

\section{Additional file 9}

Primer sequences. Table presenting the sequences of the primers used in the study.

Click here for file

[http://www.biomedcentral.com/content/supplementary/14712199-8-54-S9.pdf]

\section{Acknowledgements}

We would like to acknowledge Isabelle Piuz, Abbas Massiha, Asllan Gjinovci, and Isobel Franklin for technical assistance, as well as Philippe Halban, Gerald Thiel and Charles Vinson for the gift of material. We thank Patrick 
Descombes, Céline Delucinge and Christelle Barraclough from the Genomics Platform NCCR Frontiers in Genetics (University of Geneva, Geneva), where microarray experiments were performed. We are particularly grateful to Claes B. Wollheim for important discussions orienting the study and to Marc Prentki for critical reading of a previous version of the manuscript. Financial support was from Swiss National Foundation, grants No $3100 \mathrm{~A} 0$ I02 I47/I to WS, No 3 I00A-I07682 to BRG, and No 32-66907.0I to Claes B. Wollheim and BRG, and from the Fondation pour Recherches Médicales, Geneva.

\section{References}

I. Drucker DJ: Glucagon-like peptides: regulators of cell proliferation, differentiation, and apoptosis. Mol Endocrinol 2003, I7(2): |6I-|7|.

2. Hinke SA, Hellemans K, Schuit FC: Plasticity of the beta cell insulin secretory competence: preparing the pancreatic beta cell for the next meal. J Physiol 2004, 558(Pt 2):369-380.

3. Schuit F, Flamez D, De Vos A, Pipeleers D: Glucose-regulated gene expression maintaining the glucose-responsive state of beta-cells. Diabetes 2002, 5 I Suppl 3:S326-32.

4. Bouwens L, Rooman I: Regulation of pancreatic beta-cell mass. Physiol Rev 2005, 85(4): I 255-I 270.

5. Jonas JC, Sharma A, Hasenkamp W, Ilkova H, Patane G, Laybutt R, Bonner-Weir S, Weir GC: Chronic hyperglycemia triggers loss of pancreatic beta cell differentiation in an animal model of diabetes. J Biol Chem 1999, 274(20): |4||2-|4|2|.

6. Weir GC, Bonner-Weir S: Five stages of evolving beta-cell dysfunction during progression to diabetes. Diabetes 2004, 53 Suppl 3:SI6-2I.

7. Ohsugi M, Cras-Meneur C, Zhou Y, Warren W, Bernal-Mizrachi E, Permutt MA: Glucose and insulin treatment of insulinoma cells results in transcriptional regulation of a common set of genes. Diabetes 2004, 53(6): 1496-1508.

8. Webb GC, Akbar MS, Zhao C, Steiner DF: Expression profiling of pancreatic beta cells: glucose regulation of secretory and metabolic pathway genes. Proc Natl Acad Sci U S A 2000, 97( I I):5773-5778.

9. Susini S, Roche E, Prentki M, Schlegel W: Glucose and glucoincretin peptides synergize to induce c-fos, c-jun, junB, zif-268, and nur-77 gene expression in pancreatic beta(INS-I) cells. Faseb J 1998, I 2(12): I I73-I I82.

10. Josefsen K, Sorensen LR, Buschard K, Birkenbach M: Glucose induces early growth response gene (Egr-I) expression in pancreatic beta cells. Diabetologia 1999, 42(2): 195-203.

II. Blenis J: Signal transduction via the MAP kinases: proceed at your own RSK. Proc Natl Acad Sci U S A 1993, 90( I3):5889-5892.

12. Hazzalin CA, Mahadevan LC: MAPK-regulated transcription: a continuously variable gene switch? Nat Rev Mol Cell Biol 2002, 3(1):30-40.

13. Glauser DA, Schlegel W: Sequential actions of ERKI/2 on the AP-I transcription factor allow temporal integration of metabolic signals in pancreatic beta cells. FASEB $J$ in press.

14. Susini S, Van Haasteren G, Li S, Prentki M, Schlegel W: Essentiality of intron control in the induction of c-fos by glucose and glucoincretin peptides in INS-I beta-cells. Faseb J 2000 I4(I): I28-136.

15. Bernal-Mizrachi E, Wen W, Srinivasan S, Klenk A, Cohen D, Permutt MA: Activation of Elk-I, an Ets transcription factor, by glucose and EGF treatment of insulinoma cells. Am J Physiol Endocrinol Metab 200I, 28I(6): EI 286-99.

16. Bernal-Mizrachi E, Wice B, Inoue H, Permutt MA: Activation of serum response factor in the depolarization induction of Egr-I transcription in pancreatic islet beta-cells. J Biol Chem 2000, 275(33):2568I-25689.

17. Jonas JC, Laybutt DR, Steil GM, Trivedi N, Pertusa JG, Van de Casteele M, Weir GC, Henquin JC: High glucose stimulates early response gene c-Myc expression in rat pancreatic beta cells. Jiol Chem 200I, 276(38):35375-3538|.

18. Glauser DA, Schlegel W: Mechanisms of transcriptional regulation underlying temporal integration of signals. Nucleic Acids Research 2006, 34(18):5175-5183.

19. Swiss-Prot [http://www.expasy.org/sprot/]
20. Kim J, Seo J, Lee YS, Kim S: TFExplorer: integrated analysis database for predicted transcription regulatory elements. Bioinformatics 2005, 21 (4):548-550.

21. Kaminska B, Pyrzynska B, Ciechomska I, Wisniewska M: Modulation of the composition of AP-I complex and its impact on transcriptional activity. Acta Neurobiol Exp (Wars) 2000, 60(3):395-402

22. Olive M, Krylov D, Echlin DR, Gardner K, Taparowsky E, Vinson C: A dominant negative to activation protein-I (API) that abolishes DNA binding and inhibits oncogenesis. J Biol Chem 1997. 272(30): $18586-18594$.

23. Halazonetis TD, Georgopoulos K, Greenberg ME, Leder P: c-Jun dimerizes with itself and with c-Fos, forming complexes of different DNA binding affinities. Cell 1988, 55(5):917-924.

24. D'Alonzo RC, Selvamurugan N, Karsenty G, Partridge NC: Physical interaction of the activator protein-I factors c-Fos and c-Jun with Cbfal for collagenase-3 promoter activation. J Biol Chem 2002, 277(I):816-822

25. Stein B, Baldwin AS Jr., Ballard DW, Greene WC, Angel P, Herrlich P: Cross-coupling of the NF-kappa B p65 and Fos/Jun transcription factors produces potentiated biological function. Embo J 1993, I2(10):3879-3891.

26. Joiakim A, Mathieu PA, Elliott AA, Reiners J| Jr.: Superinduction of CYPIAI in MCFIOA cultures by cycloheximide, anisomycin, and puromycin: a process independent of effects on protein translation and unrelated to suppression of aryl hydrocarbon receptor proteolysis by the proteasome. Mol Pharmacol 2004, 66(4):936-947.

27. Hershko DD, Robb BW, Wray CJ, Luo GJ, Hasselgren PO: Superinduction of IL-6 by cycloheximide is associated with mRNA stabilization and sustained activation of p38 map kinase and NF-kappaB in cultured caco-2 cells. J Cell Biochem 2004, 9I(5):95I-96I.

28. Srinivasan S, Bernal-Mizrachi E, Ohsugi M, Permutt MA: Glucose promotes pancreatic islet beta-cell survival through a PI 3 kinase/Akt-signaling pathway. Am J Physiol Endocrinol Metab 2002, 283(4):E784-93.

29. Chipuk JE, Bouchier-Hayes L, Kuwana T, Newmeyer DD, Green DR: PUMA couples the nuclear and cytoplasmic proapoptotic function of p53. Science 2005, 309(574I): 1732-1735.

30. Tran H, Brunet A, Grenier JM, Datta SR, Fornace AJ Jr., DiStefano PS, Chiang LW, Greenberg ME: DNA repair pathway stimulated by the forkhead transcription factor FOXO3a through the Gadd45 protein. Science 2002, 296(5567):530-534.

31. Glauser DA, Schlegel W: The emerging role of FOXO transcription factors in pancreatic beta cells. J Endocrinol 2007, 193(2):195-207.

32. Rhee SG, Kang SW, Jeong W, Chang TS, Yang KS, Woo HA: Intracellular messenger function of hydrogen peroxide and its regulation by peroxiredoxins. Curr Opin Cell Biol 2005, 17(2): 183-189.

33. Findlay VJ, Townsend DM, Morris TE, Fraser JP, He L, Tew KD: A novel role for human sulfiredoxin in the reversal of glutathionylation. Cancer Res 2006, 66(I 3):6800-6806.

34. Evans JL, Goldfine ID, Maddux BA, Grodsky GM: Are oxidative stress-activated signaling pathways mediators of insulin resistance and beta-cell dysfunction? Diabetes 2003, 52(I):I-8.

35. Lilla V, Webb G, Rickenbach K, Maturana A, Steiner DF, Halban PA, Irminger JC: Differential gene expression in well-regulated and dysregulated pancreatic beta-cell (MIN6) sublines. Endocrinology 2003, I 44(4): I368-1379.

36. Pipeleers DG, in't Veld PA, Van de Winkel M, Maes E, Schuit FC, Gepts W: A new in vitro model for the study of pancreatic $A$ and B cells. Endocrinology 1985, II 7(3):806-816.

37. Gauthier BR, Brun T, Sarret EJ, Ishihara H, Schaad O, Descombes $P$ Wollheim CB: Oligonucleotide microarray analysis reveals PDXI as an essential regulator of mitochondrial metabolism in rat islets. J Biol Chem 2004, 279(30):3 I I 2 I-3 I I 30.

38. Liu WM, Mei R, Di X, Ryder TB, Hubbell E, Dee S, Webster TA, Harrington CA, Ho MH, Baid J, Smeekens SP: Analysis of high density expression microarrays with signed-rank call algorithms. Bioinformatics 2002, I 8( I 2): I593-1599.

39. Hubbell E, Liu WM, Mei R: Robust estimators for expression analysis. Bioinformatics 2002, I 8(1 2): I 585-1592.

40. Brun T, Franklin I, St-Onge L, Biason-Lauber A, Schoenle EJ, Wollheim $\mathrm{CB}$, Gauthier BR: The diabetes-linked transcription factor 
PAX4 promotes beta\}-cell proliferation and survival in rat and human islets. J Cell Biol 2004, 167(6): I I23-I I 35.

4I. TFExplorer [http://tfexplorer.org/]

42. Schreiber E, Matthias $P$, Muller MM, Schaffner W: Identification of a novel lymphoid specific octamer binding protein (OTF-2B) by proteolytic clipping bandshift assay (PCBA). Embo J 1988, 7(13):422I-4229.

43. Steinmuller L, Cibelli G, Moll JR, Vinson C, Thiel G: Regulation and composition of activator protein I (AP-I) transcription factors controlling collagenase and c-Jun promoter activities. Biochem J 200I, 360(Pt 3):599-607.

44. Reffas S, Schlegel W: Compartment-specific regulation of extracellular signal-regulated kinase (ERK) and c-Jun N-terminal kinase (JNK) mitogen-activated protein kinases (MAPKs) by ERK-dependent and non-ERK-dependent inductions of MAPK phosphatase (MKP)-3 and MKP-I in differentiating PI 9 cells. Biochem J 2000, 352 Pt 3:70I-708.

45. Array Express [http://www.ebi.ac.uk/arrayexpress]

Publish with Bio Med Central and every scientist can read your work free of charge

"BioMed Central will be the most significant development for disseminating the results of biomedical research in our lifetime. "

Sir Paul Nurse, Cancer Research UK

Your research papers will be:

- available free of charge to the entire biomedical community

- peer reviewed and published immediately upon acceptance

- cited in PubMed and archived on PubMed Central

- yours - you keep the copyright

Submit your manuscript here:

http://www.biomedcentral.com/info/publishing_adv.asp
BiolMedcentral 